\title{
ANNOTATIONS
}

\section{The Practice of Medicine}

Medical practice was defined by a very witty writer of the last century as "guessing at Nature's intentions and wishes, and then endeavouring to substitute man's."

The book in which this definition was published is a collection of humorous sayings and witty paragraphs arranged alphabetically and has the odd title of "The Tin Trumpet." It was published anonymously but it is well known that we owe it to Horace Smith, who, with his brother James, wrote the "Rejected Addresses."

There must always be a certain amount of truth underlying the guesswork in this definition, especially in the matter of diagnosis. How can we be positive about any condition if there are at least two other possibilities?

Before X-rays were in common use it was quite easy for a surgeon to be uncertain as to the actual state of affairs present in such a condition as fracture of the shaft of one of the long bones in the neighbourhood of a joint. The late Mr. Marmaduke Sheild was fond of telling a story of a gentleman. who was brought to London after having injured his shoulder. One surgeon diagnosed a fracture of the humerus and another a dislocation of the shoulder. Both were right and both were wrong, for the $\mathrm{X}$-ray examination showed a fracture of the humerus high up in the region of the neck and also the head of the bone outside the glenoid cavity.

In swellings in the fundus oculi one generally has to balance the probabilities between choroidal neoplasm and retinal cyst, and sometimes even the elect are at fault. On the other hand such an ophthalmic condition as $25^{\circ}$ of convergent strabismus can hardly be mistaken for anything else.

Commenting on the last part of the definition we do not see how, in the present state of our knowledge, man can do anything better than he does. If a patient has acute iritis it is no use waiting for Nature either to cure or alleviate the disease. The surgeon will have to get busy quickly.

And however bright the ophthalmological picture in the new world we seem to be entering we imagine that we shall have to go on doing our best, and probably making occasional mistakes, as we have done in the past. State medicine will hardly be Utopian, at any rate at its start; and it will be a very bad day for ophthalmology if a surgeon's reputation is to be gauged from his capabilities at filling up forms rather than by his clinical work. 


\section{On Waiting Rooms}

The waiting room is the next in order as a continuation of our Doors and Doorplates annotation. Facilis decensus, etc., applies here, as it should be and nearly always is, a short and easy step from the front door to the waiting room; the latter is the dining room in disguise and is furnished accordingly.

We are not aware of very much literature on the subject of waiting rooms apart from some jokes in Punch about the man who called on his dentist, not to have a tooth stopped, but to do the cross-word in the Times newspaper in the waiting room.

Austin Dobson's poem "The Drama of the Doctor's Window" is the nearest approach to this sort of theme with which we are acquainted. He postulated the presence of The Lancet and " Jones, on Muscular Decay" on the waiting room table; but most people rely on the daily papers, Punch, and illustrated magazines. A vase of flowers in the centre of the table adds to the amenities of the room, but the general aspect of most waiting rooms, it must be confessed, is rather gloomy and austere. Light-fingered gentry have been known to make an appointment with a doctor and to exercise their profession on any small objects of value while they are waiting for admission to the sanctum sanctorum, so it is just as well not to leave valuable silver in evidence. In Victorian times the sideboard of a very well-known consultant was said to have been ornamented with a decanter of sherry and a plate of biscuits to enable those who had to wait a long time to sustain their failing spirits; but such would be out of the question to-day, good sherry being almost unobtainable and Gilbert's "one and seven sherry" being calculated to do one's practice more harm than good.

The question of pictures on the walls is a debatable one. Nowadays most people eschew them, but those who were brought up in Victorian ways appreciate this form of mural decoration. A few good prints add greatly to the look of the room. One very Victorian. waiting room with which we were well acquainted had many pictures, mainly of sacred subjects, on the walls; but we suppose that at the present time pictures, if any, are more likely to be secular in kind. 